\title{
El tipo iconográfico de la Fortaleza en la «nueva visualidad»**
}

\author{
María Montesinos Castañeda \\ Universitat de València \\ maria.montesinos@uv.es
}

RESUMEN: Aunque en la tradición visual de la Fortaleza imperan las influencias italianas, durante los siglos XV y XVI, en el ámbito francés algunos artistas abandonaron los atributos ya codificados en su imagen para desarrollar otros nuevos. Esto dio lugar a la «nueva visualidad», la cual proporcionó un nuevo tipo iconográfico para la concreción visual de la Fortaleza. Dicha innovación no es más que la manifestación icónica de las características que los pensadores atribuyen a esta virtud. Asimismo, la coexistencia de la «nueva visualidad» y la tradición visual italiana dio lugar a la interacción de atributos entre tipos iconográficos.

PALABRAS CLAVE: Fortaleza; Virtudes cardinales; Alegoría; Iconografía; Cultura visual.

\section{Fortitude's Iconographic Type in the «New Visuality»}

ABSTRACT: Though Italian influences prevail in Fortitude's visual tradition, during $15^{\text {th }}$ and $16^{\text {th }}$ centuries, some artists in the French ambit abandoned its codified attributes in order to develop new ones. This gave rise to a «new visuality», which provided a new iconographic type for visual coalescence of Fortitude. Such innovation is the iconic manifestation of the features that thinkers assign to this virtue. Likewise, the coexistence of a «new visuality» and Italian visual tradition gave rise to the interaction of attributes between iconographic types.

KEYWORDS: Fortitude; Cardinal Virtues; Allegory; Iconography; Visual Culture.

Recibido: 28 de febrero de 2020 / Aceptado: 7 de junio de 2020.

Frente a la popularidad de la imagen de la Justicia - de la que existen abundantes estudios-, la visualidad de la Fortaleza es uno de los temas prácticamente ausentes en la bibliografía artística, en la que tan solo encontramos breves menciones a su visualidad más frecuente. Sus primeras representaciones se remontan al s. IX, ofreciendo una continuidad y variación en su visualidad que ha dado lugar a numerosos tipos iconográficos (Montesinos, 2019a: 103-129). A principios del s. XV, con la aparición de la «nueva visualidad» en el ámbito francés, la imagen de la Fortaleza sufrió considerables cambios que darían lugar a un nuevo tipo iconográfico. Aunque este nuevo tipo coexistiría con los previamente establecidos, ofreció continuidad durante los siglos XV y XVI, llegándose a combinar con la visualidad italiana. Generalmente, los fundamentos de la visualidad de la Fortaleza se basan en las consideraciones filosóficas sobre esta virtud, las cuales denotan la doble faceta teórica de esta virtud: la fortaleza física y la moral.

\section{La «nueva visualidad»}

Las innovaciones visuales que sufrieron las virtudes a lo largo de los siglos XV y XVI en el ámbito francés, fueron denominadas por Mâle como la «nueva iconografía»${ }^{1}$ Sin embargo, para hacer referencia a esta innovación usaremos la de-

Cómo citar este artículo: MONTESINOS CASTAÑEDA, María, "El tipo iconográfico de la Fortaleza en la "nueva visualidad”", Boletín de Arte-UMA, n. ${ }^{41}$, Departamento de Historia del Arte, Universidad de Málaga, 2020, pp. 151-160, ISSN: 0211-8483, e-ISSN: 2695-415X, DOI: http://dx.doi.org/10.24310/BoLArte.2020.v41i.8278 


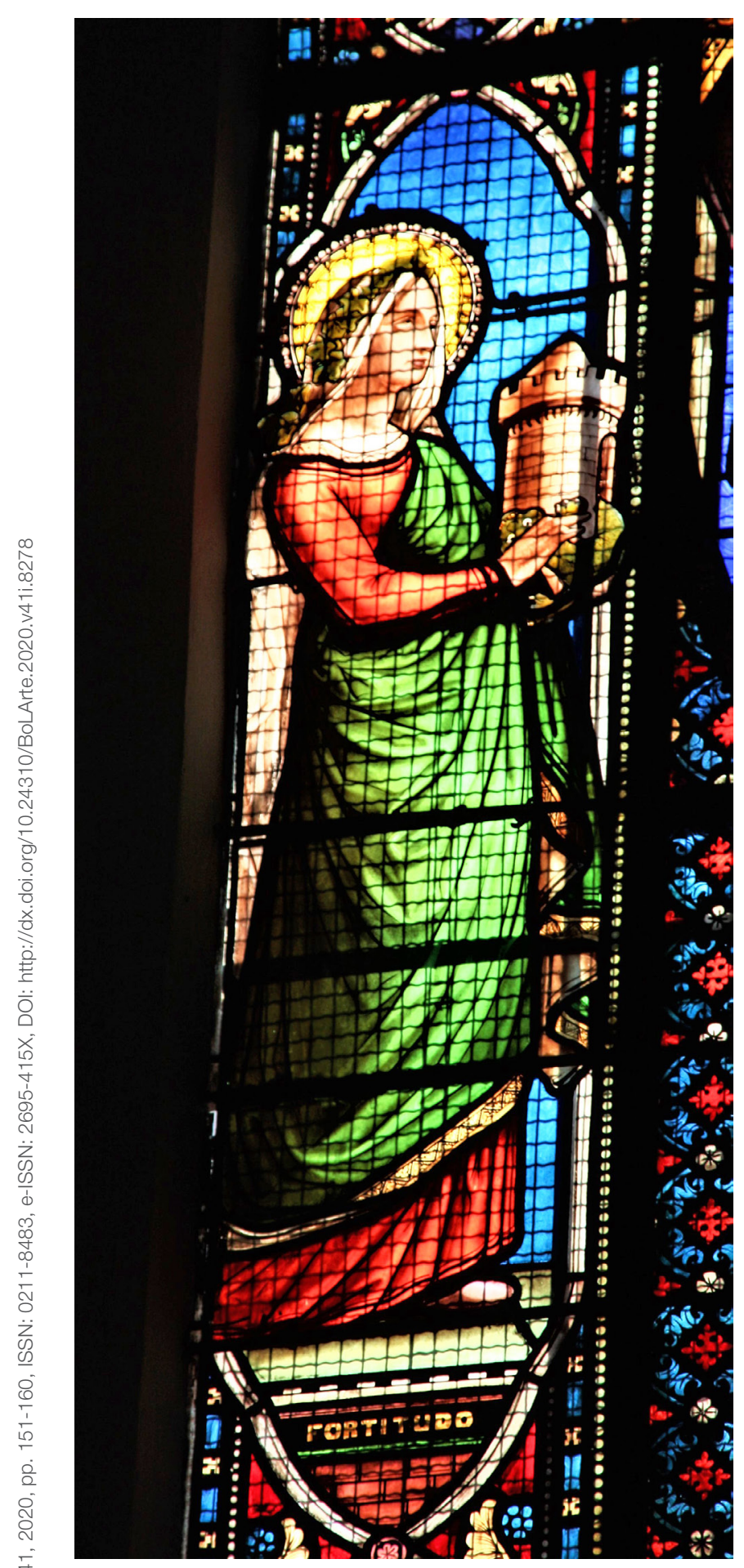

1. La Fortaleza, s. XIX, Église Saint-Paul de Montluçon nominación «nueva visualidad», ya que «nueva iconografía» emplea el término «iconografía» como contenido visual, no como una metodología de estudio (García Mahíques, 2009: 343). Dichas novedades rompían totalmente con la tradición visual establecida anteriormente, tanto francesa como italiana, aportando una serie de atributos diferentes a los ya aparecidos en sus imágenes. Mâle sitúa los inicios de la «nueva visualidad» hacia 1470 (1925: 316), aunque se ha mantenido como mediados del siglo XV a partir del estudio de diferentes manuscritos que muestran esta nueva imagen ya hacia 1450 (Tuve, 1963: 284). Por otra parte, Tuve insiste en que esta tendencia visual se originó bastante antes de las suposiciones de Mâle, pues, aunque la fecha exacta no ha sido determinada, dicha autora la fija hacia 1400-1402 (1963: 287-288).

La representación de las virtudes durante la Edad Media contrasta con la imaginería alegórica que caracteriza la «nueva visualidad» de cuantiosas obras del siglo XV. Esta representa a las virtudes cardinales como doncellas vestidas a la manera contemporánea acompañadas de una extraordinaria colección de atributos. La «nueva visualidad», estuvo de moda en Francia y Países Bajos, aunque la complejidad de sus atributos fue gradualmente modificada por los tipos iconográficos italianos (North, 1979: 234). El alto grado de innovación visual fue calificado por Mâle como arbitrario y brusco (1925: 311-318), explicando la creación de nuevos atributos como respuesta a la carencia de una tradición precedente directa (1925: 311). Aunque encontramos diversas miniaturas de las virtudes sin atributos en un texto titulado San Agustín (1469) (Burris, 1997: 39), tan solo se trata de una excepción, puesto que la fortaleza, al igual que las otras virtudes, comienza a representarse con atributos identificativos ya en el siglo IX (Montesinos, 2019b: 60-71), acrecentando su visualidad y representación en los siglos posteriores. Sin embargo, Tuve, además de cambiar la cronología de inicio de esta tendencia, ha mostrado que el propósito de esta no supone una gran desviación de la tradicional representación de las virtudes (O’Reilly, 1988: 120). Los italianos fueron fieles a los tipos iconográficos que la Francia del siglo XIII había creado, como la Fortaleza con imagen guerrera o enfrentándose a un león, tal y como aparecen en las portadas de las catedrales francesas. Sin embargo, las virtudes francesas del siglo XV portan nuevos atributos en ambas manos, diferentes a los italianos, 
lo que Mâle califica del siguiente modo: «Alors que les Vertus françaises du XVe siècle n'ont pas assez de leurs deux mains pour porter leurs jouets d'enfant, les Vertus italiennes abandonnent tout ce qui n'est pas essentiel, expriment surtout par leur attitude l'élan interieur» (1925: 322). Pero, según Tuve, los bizarros objetos simbólicos no son «atributos» como Mâle los llama, sino que se adaptan a las funciones de los aspectos definidos de cada Virtud (1963: 283). No obstante, entendemos el término «atributo» como «un recurso de la retórica visual consistente en la representación de objetos que traducen cualidades abstractas, o bien aluden a algo» (García Mahíques, 2009: 339). Por lo tanto, los objetos que sostienen las virtudes son calificados de atributos, puesto que sigan o no la tradición, fruto de la continuidad o la variación, representan cualidades de las personificaciones a las que acompañan.

La irrupción de tales innovaciones visuales no ofreció continuidad más allá de los siglos XV y XVI, principalmente en el ámbito nórdico, aunque también en territorio español. Sin embargo, es curioso que, a pesar de que la «nueva visualidad" cayera en desuso ya a finales del siglo XVI, la combinación del dragón y la torre se mantuvo en alguna obra de cronología posterior, como es el caso de una vidriera de la Église Saint-Paul de Montluçon (s. XIX) [1]. Pero este tan solo es un caso excepcional, puesto que por lo general no encontramos continuidad de los atributos aportados por esta corriente en siglos posteriores. Gombrich expone claramente las razones por las que la «nueva visualidad» pasó rápidamente de moda:

Paradójicamente, fue esta misma modernidad la responsable de que la «nueva iconografía» pasara de moda tan rápidamente con la llegada del Renacimiento pleno. Los humanistas recordaron el parentesco entre las personificaciones y los dioses antiguos, e igual que se devolvió a los olímpicos su forma y belleza pretéritas, también la imagen alegórica había de aparecer al modo clásico. Por mucho que admirara el siglo XVI lo extraño y enigmático, monstruos como los realizados por Leonardo difícilmente hubieran resultado aceptables, y menos aún hubiera sido posible equipar las personificaciones con divisas de nueva creación, pues había que conservar el aspecto de una imagen all'antica: tanto la forma como el simbolismo de la personificación tenían que llevar el marchamo de una autoridad antigua (2001: 139).

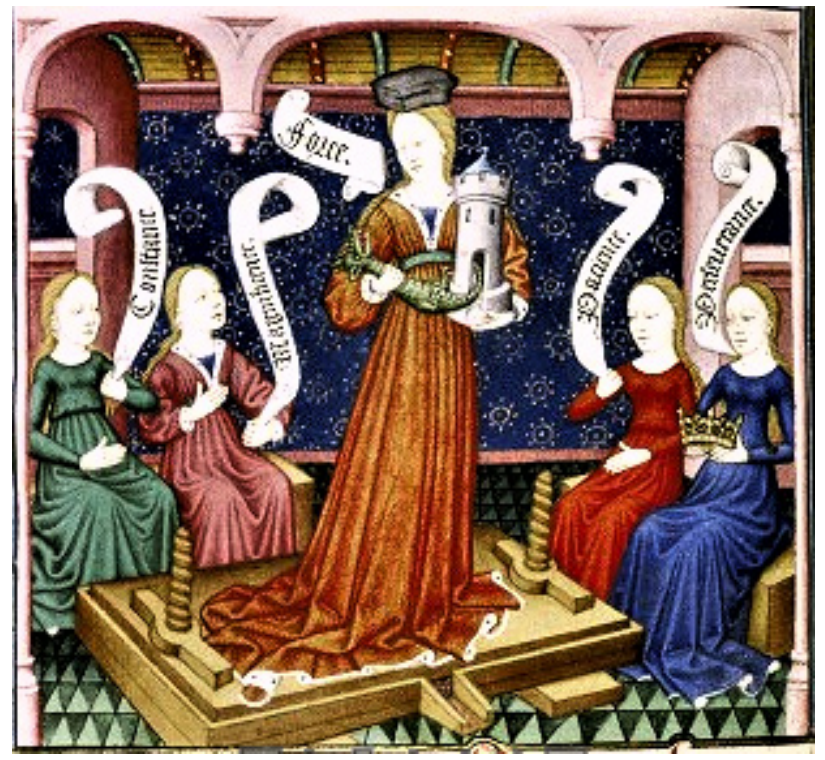

2. La Fortaleza, Livre des trois vertus, Cristina de Pizán, 1450, Oxford, Bli, ms. Laud Misc. 570

Bonardi ha calificado esta decadencia de la «nueva visualidad» como consecuencia de que "L'influence italienne renouvelle l'iconographie des vertus en France et en Europe» (2010: 58), como si la preeminencia de la visualidad italiana se basara principalmente en la continuación de la visualización de las virtudes o la propia visualidad italiana aportara muchas más novedades de las ya existentes.

\section{La visualidad de la Fortaleza en la «nueva visualidad»}

Aunque la Fortaleza presenta unos claros antecedentes visuales y una visualidad establecida y consolidada a lo largo de la Edad Media², la «nueva visualidad» rompió con la tradición aportando un nuevo tipo iconográfico para representar esta virtud. Ya a mediados del siglo XV, en el famoso manuscrito Laud 570 del Livres des trois vertus de Cristina de Pizán (1450, Oxford University, Bli) [2] encontramos a la Fortaleza representada sobre una prensa o lagar mientras agarra a un dragón que emerge de una pequeña torre y sostiene un yunque sobre su cabeza. Si bien todos los atributos son nuevos en la visualización de la fortaleza, la imagen del Laud 570 no es un caso único ya que dicho tipo iconográfico se mantuvo 


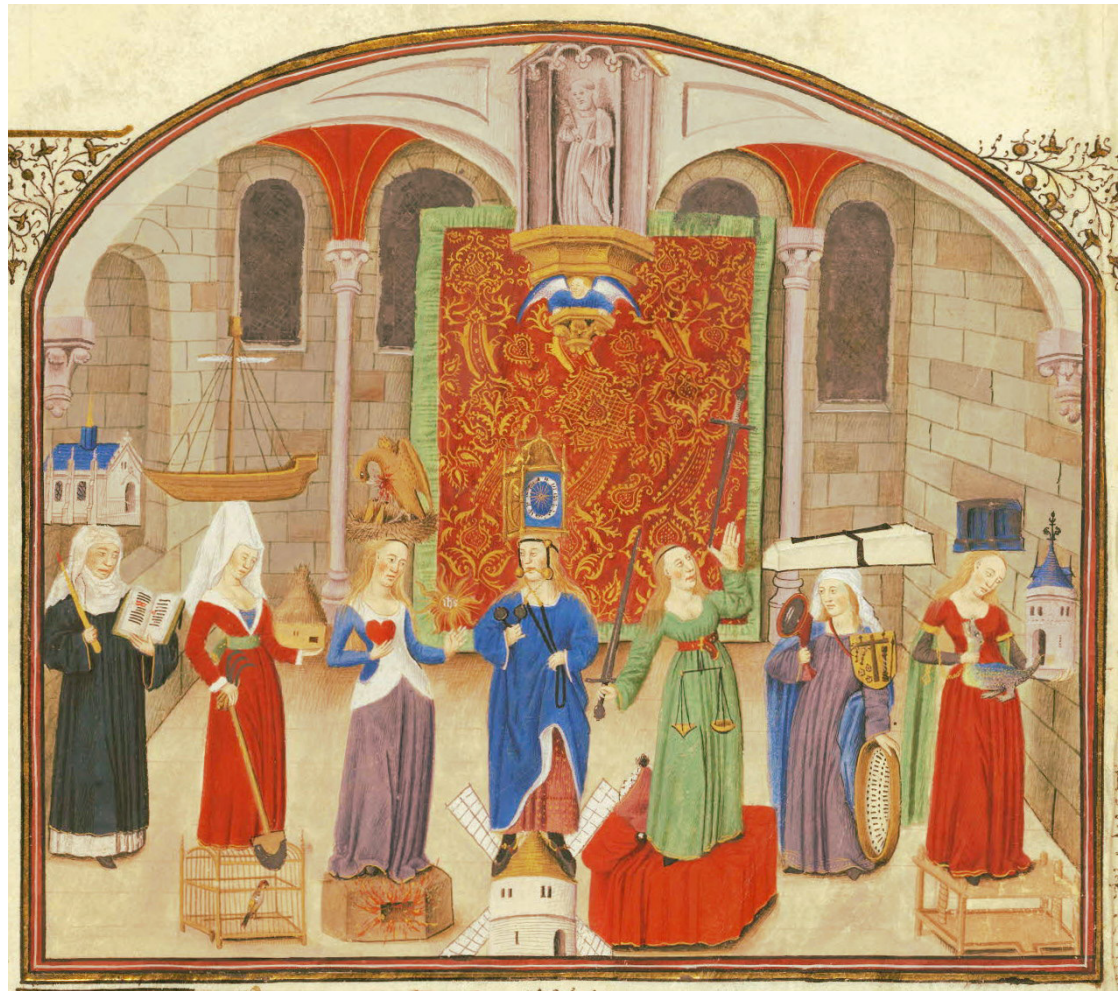

3. Las siete Virtudes, Ethique Aristotle, Nicole Oresme, 1452, Rouen, BM, ms. fr. 927. I 2, fol. $17 \mathrm{v}$. durante los siglos XV y XVI ${ }^{3}$. Muestra de ello son Las siete Virtudes de Nicole Oresme (Ethique Aristotle, 1452, Rouen, BM, ms. fr. 927. I 2, fol 17v) [3] y el Manuscrito del duque de Nemours (ca. 1477, París, BNF, ms. fr. 9186, fol. 304).

La complejidad de las imágenes creadas dentro del ámbito de la «nueva visualidad», en muchos casos requería un texto explicativo de los atributos con el fin de que el espectador pudiera comprender el significado de su presencia. Aunque esto no siempre se cumple, en el Manuscrito del duque de Nemours (ca. 1477, París, BNF, ms. fr. 9186, fol. 304) la fortaleza se acompaña del siguiente texto:

L'enclume se rend clere et fine / par souvent prendre discipline. / La forcé de cuer est al tour / qui n'est vaincue par nul tour. / Qui mest hors de sa conscience / le mauvais ver est grant science. / Au pressoir de contrition / sont lermes (larmes) de dévotion. / Ainsi qu'un pressoir ferme à vis / forcé se conduit par aviz.

La presencia de cada nuevo atributo tenía su significado en relación con las características de la fortaleza. La torre o turris fortitudinis a la que se refiere representa la constancia (Tuve, 1977: 74), una de las partes de la fortaleza ${ }^{4}$. Asimismo, Fray Íñigo de Mendoza explica la torre junto a la Fortaleza como signo de la firmeza que representa la parte más espiritual de esta virtud: "os labraran / vna torre muy luzida, / en tal son fortalecida / y establescida, / que de dentro vuestra alteza / con mucho firme firmeza / y destreza / se halle fauoregida / quando se viere afligida» (Mendoza, 1912: 74). En cuanto al monstruo que sale de esta torre, reconocido como un dragón, representa al pecado que intenta entrar en la fortaleza de la consciencia, razón por la cual el hombre debe arrancarlo de allí (Mâle, 1925: 316). No es de extrañar que se representara un dragón como personificación del pecado, si ya las fuentes bíblicas lo identifican con el diablo o Satanás (García Arranz, 2019: 194): «Entonces hubo una batalla en el Cielo: Miguel y sus ángeles lucharon contra el dragón. El dragón y sus ángeles combatieron, pero no pudieron prevalecer y no hubo puesto para ellos en el cielo» (Ap 12,7-9). Aunque se trate de un tipo iconográfico nuevo, la Fortaleza se enfrenta al Mal, bien sea representado por un dragón que trata de corromper la fortaleza del alma, o por el 
león que representa al vicio al que se opone, como ocurre en los tipos codificados por la tradición (Montesinos, 2019a). Todo ello no es más que la manifestación visual del pensamiento en torno a esta virtud, la cual san Gregorio Magno definió del siguiente modo: "La fortaleza de los justos consiste en vencer a la carne, combatir la sensualidad, extinguir el goce de la vida presente» (GREG. M. moral. 7,21; PL LXX$V, 778)^{5}$. Igualmente, santo Tomás de Aquino, al definir los objetivos y funciones de la fortaleza, explica:

Es propio de la fortaleza impedir que la voluntad se aparte del bien de la razón por temor de un mal corporal. [...] Es, pues, necesario que la fortaleza del alma sea la que conserve a la voluntad del hombre en el bien racional contra los mayores males, ya que quien resiste a ellos resistirá evidentemente a los menores, pero no viceversa; porque es propio también de la virtud tener en cuenta y tender a lo último (S. Th. [44074] $\|^{\mathrm{a}}{ }_{-}$ Ilae, q. 123 a. 4 co.; Barbado Viejo, 1955-1960: 704).

Así, Tomás de Aquino conserva la concepción de la fortaleza como la virtud que vence el temor, a la vez que incorpora la concepción medieval de preservar al hombre del mal, materializado de tan variada forma (García Arranz, 2019: 296).

Al igual que la torre, el yunque representa dos de las partes que componen la fortaleza: la firmeza y la paciencia (Tuve, 1963: 288). Aunque el yunque pueda parecer la fuerza que resiste, realmente se refiere a la fuerza realizada por placer, es decir, aquella fuerza que lucha por embellecer, como el martillo con el tiempo afina y pule el yunque (Mâle, 1925: 316). El hecho de soportar el peso del yunque nos indica que ejercita la fuerza al nivel de que es capaz de superar a la prensa y gracias a dicha fuerza es capaz de sacar al monstruo del castillo (Sebastián, 1988: 306). Según Mâle (1925: 316), la prensa no significa la fuerza bruta como indica Sebastián (1988: 306), sino que representa el triunfo del alma sobre sí misma ya que es la constricción la que hace fluir las lágrimas, al igual que el líquido brota bajo el tornillo de la prensa. De acuerdo con Tuve, la asociación de las virtudes con los dones del Espíritu Santo y la especial correspondencia de esta virtud con el don de la fortaleza (S.Th. [44583] ॥ª llae, q. 139 a. 1 co.), -supremamente mostrada en la Pasión de Cristo- anticipó la doble faceta de la fortaleza mediante el sufrimiento corporal como la verdadera lucha contra los

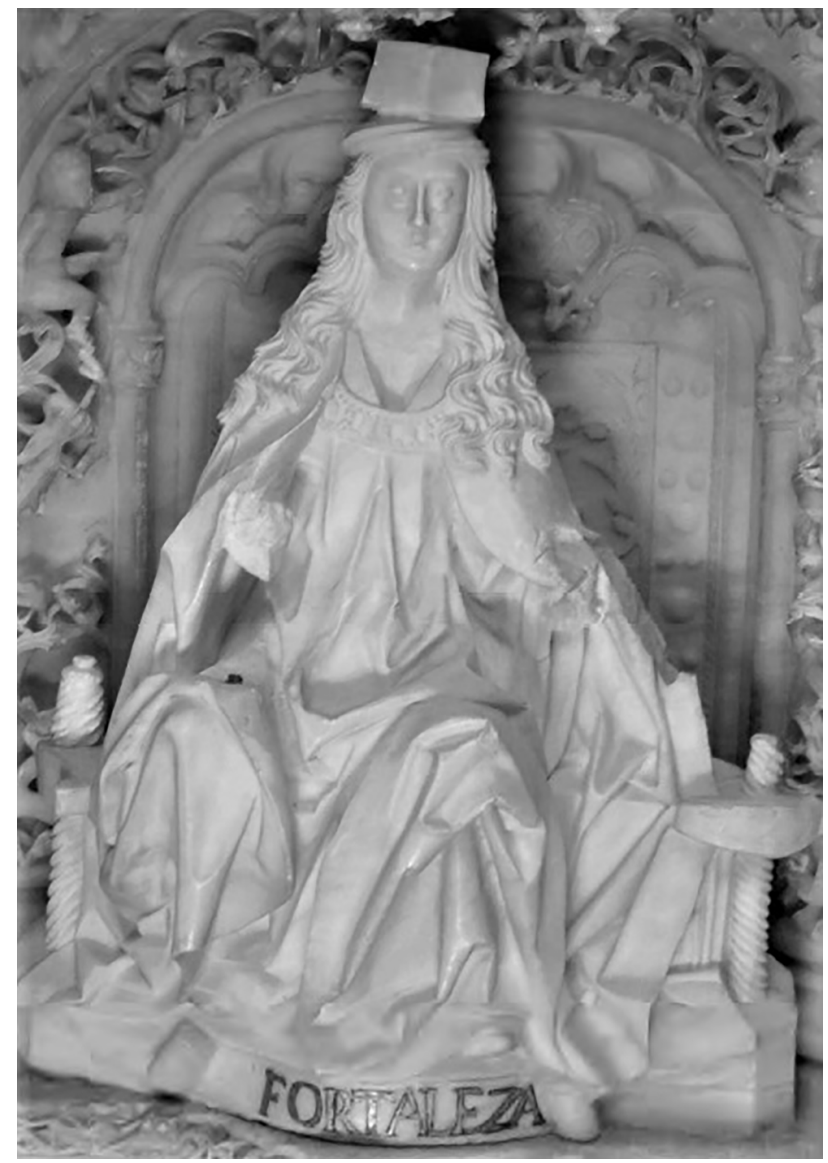

4. La Fortaleza, Sepulcro de Juan II e Isabel de Portugal, Gil de Siloé, 1489-1493, Burgos, Cartuja de Miraflores

males (Tuve, 1977: 96-97). Además, la prensa también representa la perseverancia y la paciencia (Tuve, 1977: 74), otras de las partes que componen la virtud de la fortaleza. Aunque pueda parecer extraordinario, también encontramos este tipo iconográfico de la fortaleza en una ilustración de Le séjour de deuil pour le trespas de Messire Philippes de Commines (1512, La Haya, KB, ms. 76 E 13, fol. 7r) y en el Sepulcro de Juan I/ e Isabel de Portugal, (Gil de Siloé, 1489-1493, Burgos, Cartuja de Miraflores) [4], pero en este caso parece que la torre con el dragón no se conserva.

Tras la configuración de este nuevo tipo iconográfico, los artistas no se sorprendieron de la sobrecarga de atributos de las virtudes, pero comenzaron por suprimir los singulares tocados con los que se cubrían. Mientras que en algunas obras no se han conservado todos los atributos, en otras se opta por reducirlos o incluso aparecen solos a 


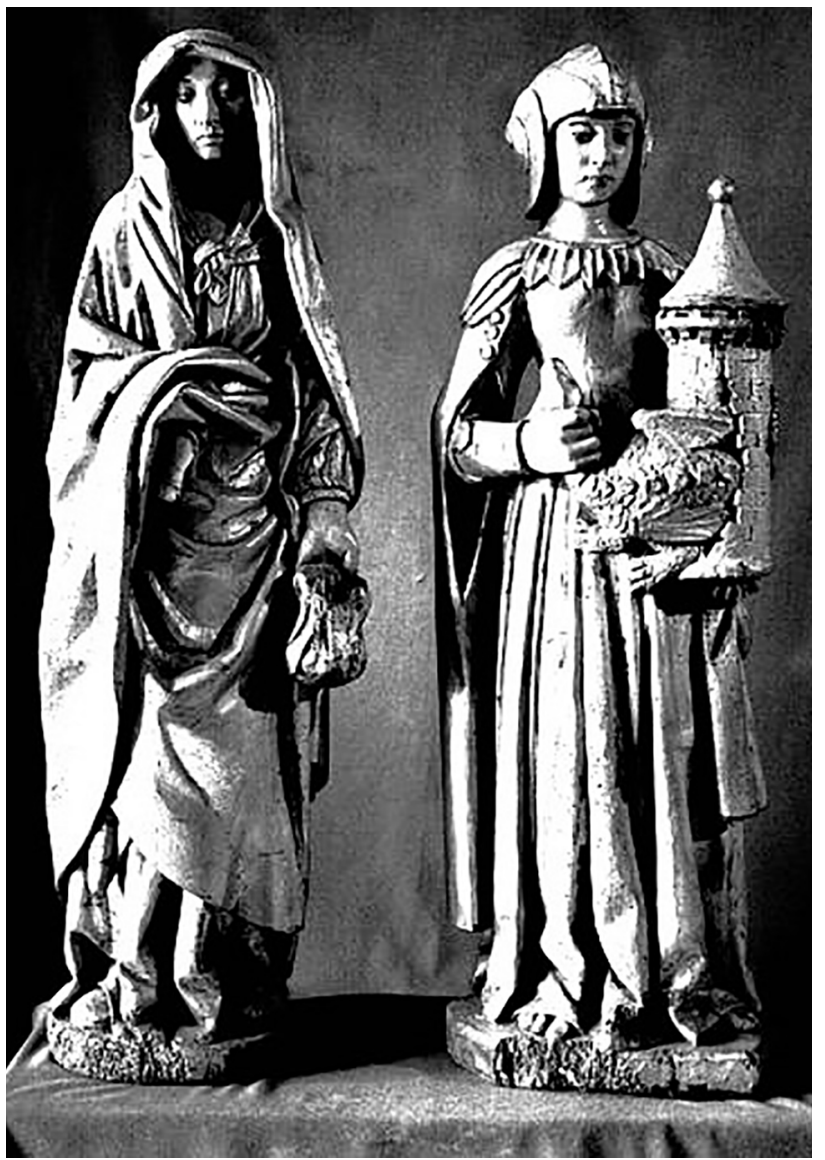

5. La Prudencia y la Fortaleza, s. XV-XVI, Tarn, Iglesia Saint-Saveur

modo de emblema de la fortaleza. La reducción más popular de atributos fue la del dragón que está siendo arrancado de una torre, como vemos en una escultura de la iglesia de Tarn (s. XV-XVI) [5], en una ilustración del Dialogue sur le jeu (s. XVI, París, BNF, Français 1863, fol. 2v) o en el tapiz de Las siete virtudes de la serie de Los Honores (círculo de Bernard van Orley y Jan Gossaert, 1517-1525, Segovia, Palacio de la Granja de San IIdefonso). El artista que concibió esta figura de la Fortaleza, más que hábil, fue sabio al saber combinar la fuerza física del combate (extrayendo al monstruo de la torre) con el dominio de uno mismo, representado mediante el lagar (Mâle, 1925: 328). También encontramos a la Fortaleza extrayendo al dragón de la torre en el manuscrito titulado La Sale de Antonio de la Sale (1461, Bruselas, KB, ms. 9287-9288, fol. 113), en Ces presentes heures a lusage de Amiens tout au long sans require de Simon Vostre (1502,
París, BNF, RESERVE 8-T-2526) y en la Tumba de François de Lannoy y Marie de Hangest (s. XVI, Somme, Folleville), entre otras obras ${ }^{6}$.

No tan frecuente es la representación de la Fortaleza enfrentándose directamente al dragón, como vemos en el tapiz de La gloria y los honores de las virtudes (ca. 1515) donde estrangula al dragón agarrándolo por el cuello. Si recordamos los antecedentes visuales de la Fortaleza, Hércules se enfrentó al león con una maza, pero finalmente lo estranguló: «le agarra, / se hace un nudo con él y le estrangula / con presión tan furiosa que los ojos / le salta de las cuencas, y esas fauces / deja secas al fin de sangre humana». (Virgilio, Eneida, 8, 358-363; 2003: 733). Aunque las fuentes hacen referencia al león, en este caso la Fortaleza estrangula al dragón, haciendo referencia ambos animales a los peligros a los que ha de enfrentarse esta virtud para no ser corrompida por el mal.

Incursiones visuales: entre la tradición y la «nueva visualidad»

Si bien la combinación de la torre y el dragón fue la opción más frecuente, encontramos algún caso en el que solo el yunque y el lagar representan a esta virtud. Al igual que la serpiente asociada a la Prudencia fue empleada como marca de algunos impresores (Montesinos, 2019b: 199), el lagar asociado a la Fortaleza fue el emblema del compositor Gilles Joye en uno de sus retratos (Hans Memling, 1472, William Sterling And Francine Clark Art Institute). Asimismo, en una vidriera de la Catedral de Rouen (ca. 1521) la Fortaleza tan solo sostiene un yunque sobre su cabeza, aunque también abraza una columna, atributo propio de esta virtud desde el siglo XIV (Montesinos, 2019a: 124-126). En este caso podemos comprobar cómo la tradición visual convencionalizada, en cuanto a la continuidad de la columna, se combina con la variación, el yunque como aportación de la «nueva visualidad». Más común es la combinación del dragón que arranca la Fortaleza de una torre con la apariencia guerrera de la virtud, ataviada con yelmo y coraza, como vemos en la Tumba del cardenal d'Amboise (ca. 1516, Catedral de Rouen), en la Tumba de Francisco // de Bretaña (Michel Colombe, 1502-1507, Catedral de Nantes) [6] y en el Hôtel Guymoneau (s. XVI, Riom) [7]. En el Palazzo Pubblico de Siena 
(1413-1414), Taddeo di Bartolo representó a la Fortaleza con aspecto guerrero y sosteniendo una torre, pero sin monstruo que sobresalga de ella. Sin embargo, puede que la combinación más curiosa de atributos es la obra de Antonio Barili (finales del s. XV-1516) [8], quien tan solo representó la Fortaleza mediante el busto de un soldado cuyo casco está coronado por un dragón.

Entre esta amalgama de complejidad visual que comportó la «nueva visualidad» y la continuación de la tradición visual de la Fortaleza, podríamos encuadrar La Fortaleza de Brueghel (1560, Ámsterdam, Rijksmuseum, RP-P-OB-7377) [9]. En esta obra -grabada por Philippe Galle- la Fortaleza sostiene un yunque con su cabeza mientras abraza una columna y pisa al Vicio que lleva sujeto con una cadena. Además, viste coraza y tiene unas grandes alas, lo que según Tucker (2015: 199) añaden el sentido de su poder, como el yunque muestra la fuerza de soportar cualquier golpe. Alrededor de la Fortaleza se alza una «psicomaquia» en la que la humanidad, representando a la virtud, lucha contra los vicios, encarnados en monstruos ${ }^{7}$. Aunque la concreción visual de la Fortaleza responde a la combinación de la «nueva visualidad» con la tradición visual de esta virtud, se traduce en una composición compleja que emplea los mismos elementos de forma distinta. En este caso, la Fortaleza no agarra a un monstruo que saca de una torre, pero el monstruo se encarna en los vicios partícipes en la «psicomaquia». En cuanto a la torre, queda representada mediante el castillo que se sitúa en el centro, queriendo significar el alma que no debe ser corrompida por el Vicio, razón por la que está protegida por soldados y las criaturas aladas que aparecen en las banderas de las cuatro torres, las cuales representan el Tetramorfo (Burris, 1997: 114). La abarrotada escena se acompaña de una inscripción que explica el sentido del conjunto: A NIMVM VINCERE, IRACVNDIAM COHIBERE CAETERAQ VITIA ET AFFECTUS COHIBERE VERA FORTITUDO EST [Para vencer los impulsos de uno mismo, contener la ira y los otros vicios y emociones esta es la verdadera Fortaleza]. Como bien apunta Burris, Brueghel combinó atributos típicos de la imagen de la Fortaleza en el ámbito francés y flamenco con la tradición italiana que conoció en su viaje al sur de Europa en la década de 1550 (Burris, 1997: 41). Semejante concepción representó Iglesia en el emblema «Urbs fortitudinis» [ciudad de fortaleza] acompañándose de las siguientes palabras: «En ciudad fortificada / Co muro, y antemural / No entró culpa original»

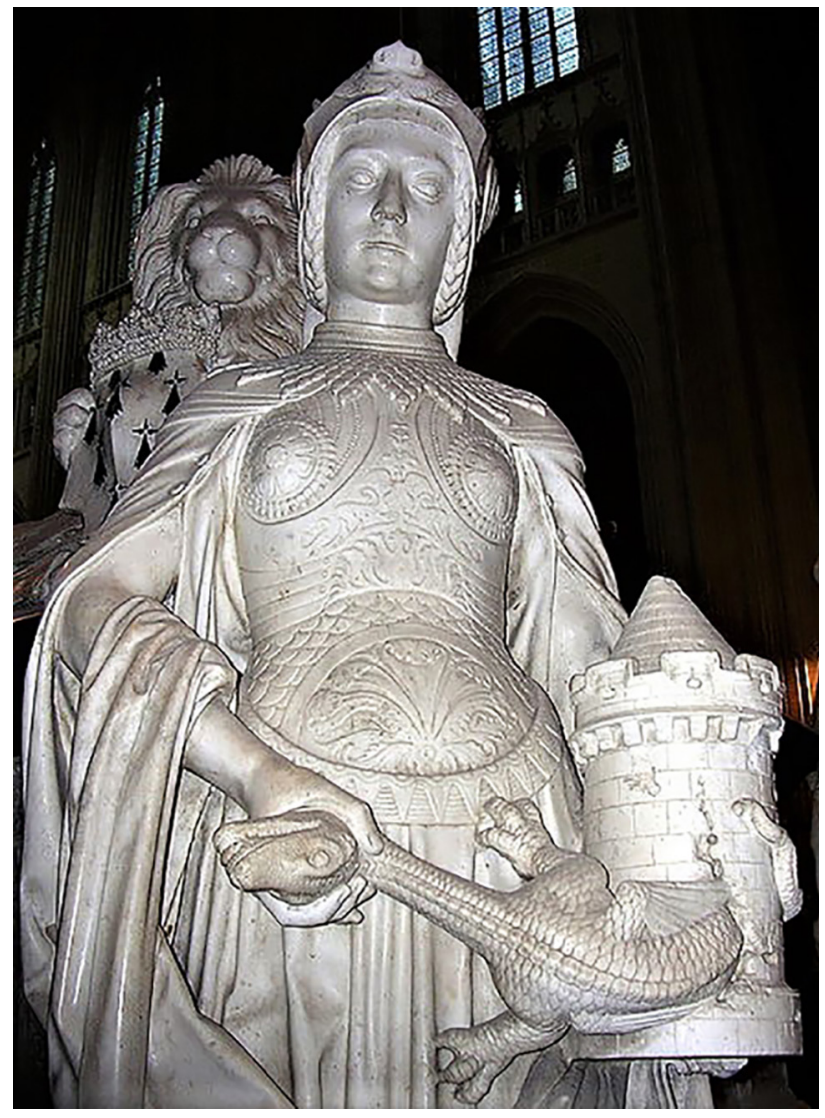

6. La Fortaleza, Tumba de Francisco I/ de Bretaña, Michel Colombe, 1502-1507, Catedral de Nantes

\section{La Fortaleza, s.XVI, Riom, Hôtel Guymoneau}

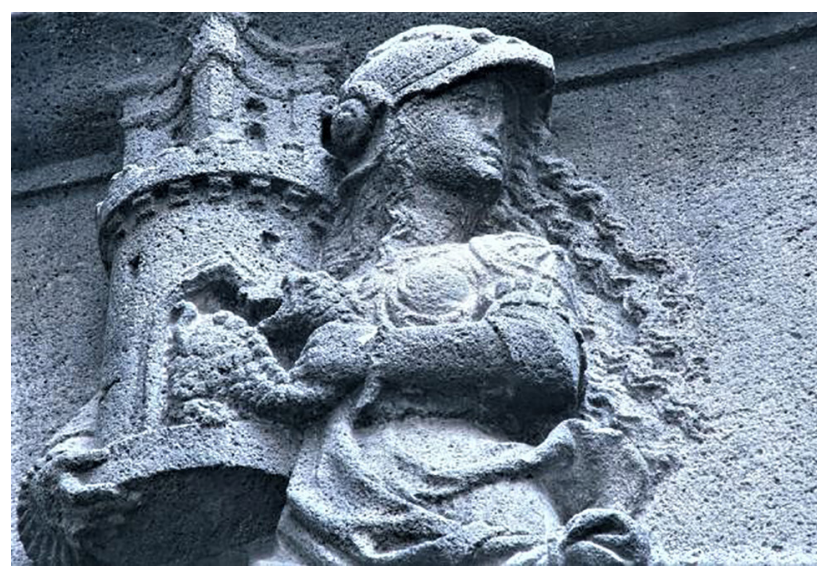




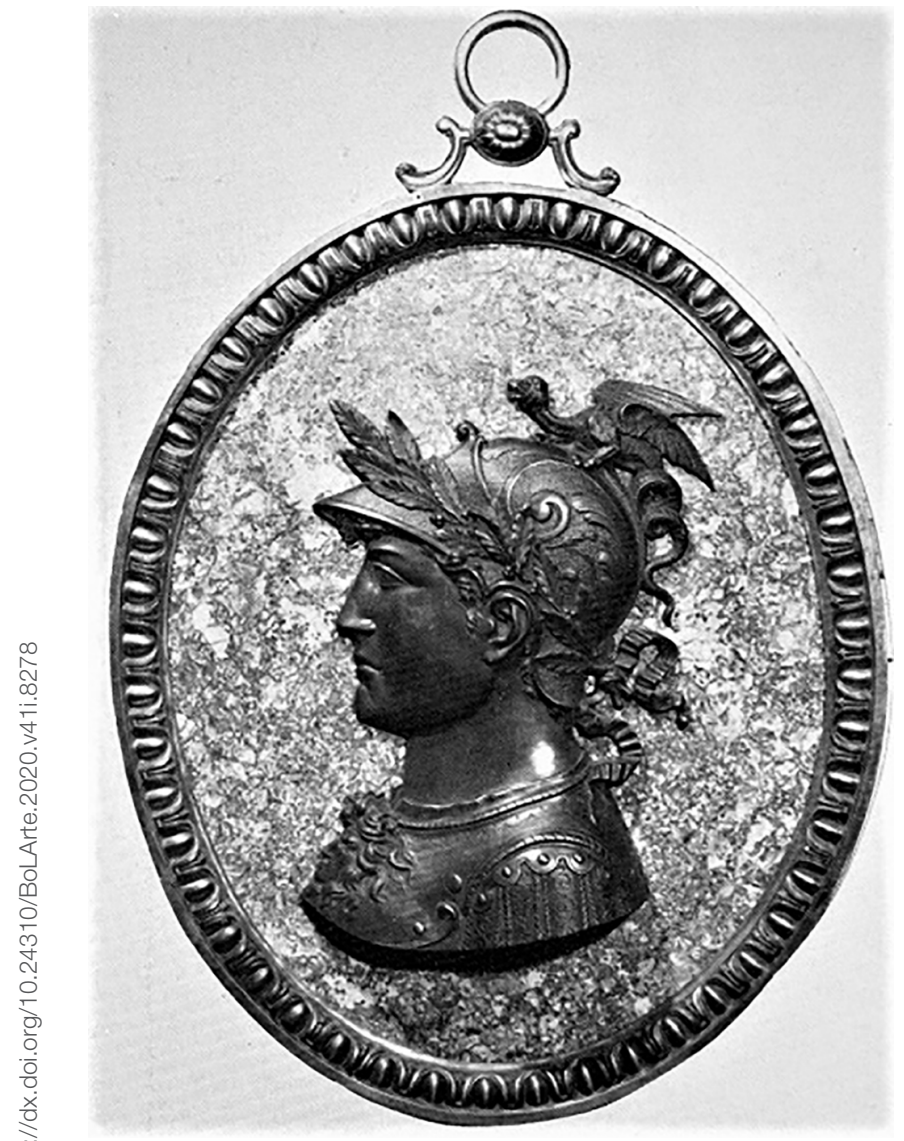

8. Alegoría de la Fortaleza, Antonio Barili, ca. 1490-1516, Siena, Accademia di Belle Arti

9. La Fortaleza, Las siete virtudes, Pieter Bruegel, 1560, Ámsterdam, Rijksmuseum, RP-P-OB-7377

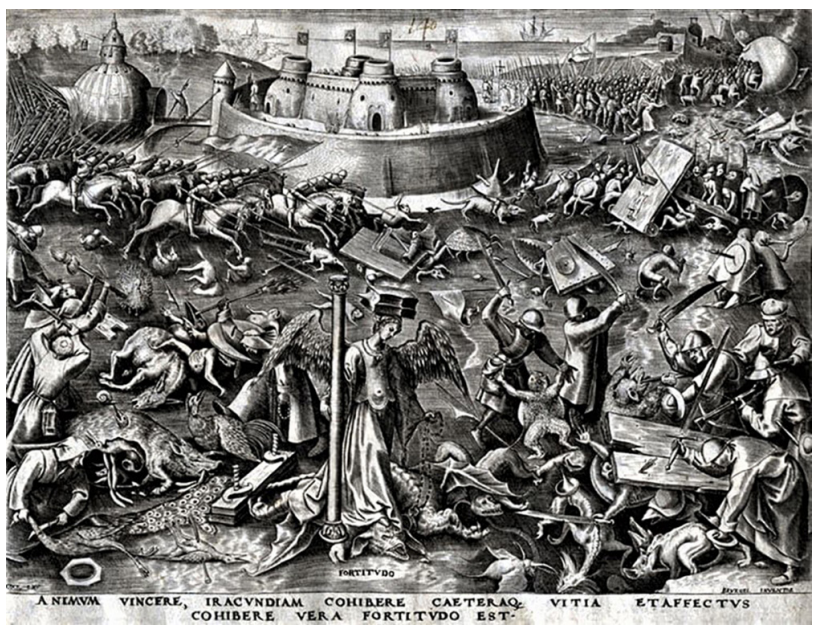

(Iglesia, 1659: 76v). De este modo, tanto Iglesia como Brueghel representaron una Fortaleza como morada de la virtud donde ningún vicio ni pecado puede entrar, queriendo expresar el mismo significado que la Fortaleza cuando arranca al dragón de la torre.

Presencia de la «nueva visualidad» de la Fortaleza en el ámbito emblemático

Por último, aunque parece que la «nueva visualidad» solo se empleó en los manuscritos y monumentos funerarios de los siglos XV y XVI, siendo la obra de Brueghel una excepción, los complejos atributos permanecieron en el ámbito de la literatura emblemática. Guillaume La Perrière representó un yunque sobre el que se posan martillos haciendo alusión al hombre constante que guía su fuerza por el camino de la vir$\mathrm{tud}^{8}$, al igual que Scipione Bargagli en el emblema «In qvasqvmqve formas ${ }^{9}$ y Sebastián de Covarrubias en el emblema «Sustine et abstine» [Resiste y abstente]:

a yunque sufre muchas martilladas / sin que haga mudança, o sentimiento, / figura de personas maltratadas, / que convierte en gusto el descontento: / y aquestas, siendo bien morigeradas, / mudando suerte, no mudan intento, / con sufrir siendo yunque, y quando fueron / martillo, de dar golpe se abstuvieron (1610: 278).

Covarrubias también representó un yunque y un martillo bajo el lema «No por esso pierde su valor y peso» ${ }^{10}$ explicando que «como la conciencia esté sana, aunque la fortuna con el martillo de los trabajos, atormente, y quebrante, hazienda, salud y vida, pues el valor de la virtud no pierde por esto, antes se mejora, con la tolerancia y paciencia» (1610: $194 v)$. De este modo, mediante instrumentos que representan la fuerza física, como son el yunque y el martillo, se hace referencia a la fuerza moral que representa la virtud de la fortaleza, lo que implica a la paciencia, la constancia o la perseverancia -partes que la forman-, como Ferro explica: «El'Incvdine segno di costanza d'animo forte, con che à tollerare le cose avverse siamo ammoniti» (1623: 412).

También encontramos un yunque y un martillo en la empresa «Tempori cede» [Ceder al tiempo] de Francisco Gómez de la Reguera (1990: 147), así como en la de Solórzano 
Pereira (1653: 328-335) que lleva el mismo mote, quien utiliza estos elementos para destacar la fortaleza que debe poseer todo gobernante. Andrés Mendo, copiando al anterior, explica bajo el mismo lema: «Disimule los sentimientos con paciencia, y ceda al tiempo con magnanimidad, y cordura» (1662: 27). Así, el yunque y el martillo representan la paciencia y magnanimidad que componen la Fortaleza. También Diego de Saavedra Fajardo, en su Idea de un príncipe político christiano, representó una rueda hidráulica, un yunque y el martillo de una fragua bajo el lema «Plura consilio quam vi» [Más por el consejo que por la fuerza], con el fin de advertir que la fuerza debe ser usada a partir de la sabiduría (Saavedra, 1677: 632). Además, esta empresa nos recuerda la dependencia que existe entre las virtudes cardinales, en este caso la fortaleza es esa combinación de la fuerza tanto física como moral, pero puesta en práctica desde la prudencia y con templanza.

\section{Conclusiones}

El tipo iconográfico de la Fortaleza en la «nueva visualidad» aporta una nueva concreción icónica de esta virtud caracterizada por nuevos atributos -la torre, el dragón, el yunque y la prensa o lagar-. No obstante, aunque se considera la «nueva visualidad" una tendencia que rompe con la tradición convencionalizada, podemos observar como no se aleja tanto. Si bien ahora la Fortaleza se enfrenta a un dragón que pretende corromper la fortaleza del alma -representada por una torre-, anteriormente combatía al león como representación del vicio al que se oponía. De este modo, la tarea que cumple esta virtud sigue siendo la misma, ofreciendo una concreción visual que, aunque novedosa, sigue siendo la manifestación icónica de las fuentes filosóficas que definen a esta virtud como aquella que debe combatir tanto física como moralmente todo peligro que trate de corromper el alma.

\section{Notas}

* Esta investigación se ha realizado gracias a la financiación de la Universitat de València y su programa de ayudas «Atracció de Talent».

1 Al ordenar la visualización de las virtudes, autores como Bonardi las han clasificado en diferentes fases. En primer lugar, se suele hacer referencia a las «Virtudes guerreras» como aquellas que luchan contra los Vicios en la "psicomaquia». A continuación, al ser portadoras de divisas identificativas se las ha llamado «Virtudes emblemáticas». Por último, para referirse a esta «nueva visualidad», se las ha llamado "Virtudes simbólicas» por estar cargadas de muchos atributos (Bonardi, 2010: 57). Sin embargo, al emplear este último término parece sobreentender que anteriormente al siglo XV las Virtudes no portaran atributos -definidos como objetos simbólicos- por lo que dicha novedad no va ligada a ese «simbolismo» que se les confiere, sino a una visualización más específica de todos los aspectos y funciones que las caracterizan. De todos modos, calificar de «simbólicos» atributos es una generalización inapropiada, ya que debe de diferenciarse entre «símbolo» y «recurso retórico» -metáfora, alegoría, etc.-, el cual en algún caso puede estar basado en un concepto simbólico, mas no siempre.

2 A lo largo de la Edad Media la Fortaleza se representó mediante diversos tipos iconográficos caracterizados por su aspecto guerrero o hercúleo principalmente, aunque ofreciendo diversas variantes como ya se han estudiado (Montesinos, 2019a: 103-129).

3 No obstante, cabe tener en cuenta que, aunque la «nueva visualidad» presentó una gran variación en la representación de las virtudes, no fue sustitutiva de las imágenes existentes, ya que durante estos siglos también hubo otras representaciones que ofrecieron continuidad en la imagen de esta virtud (Montesinos, 2019b: 466-476).

4 Los pensadores consideran que la Fortaleza está compuesta por otras virtudes, las cuales se denominan partes y son las siguientes: Perseverancia, Paciencia, Confianza, Magnificencia, Magnanimidad, Seguridad, Constancia, Firmeza, Longanimidad, Mansedumbre, Tolerancia, Nobleza, Estabilidad, Descanso y Humildad (Montesinos, 2019b: 441-445 y 499-512).

5 La traducción es nuestra.

6 La Fortaleza se representa arrancando al dragón de la torre como únicos atributos identificativos en el Fleur des histoires de Jean Mansel (s. XV-XVI, Bruselas, BR, MS 9232, fol. 448v) y en el Monumento funerario del cardenal Denonville (Laigniel Mathieu, 1543, Catedral de Amiens)

7 Las fuerzas de la Virtud, todas ellas humanas, actúan con calma y determinación, mientras que la lucha de los fantásticamente armados vicios incluye el oso de la Ira, el gallo de la Lujuria, el pavo real del Orgullo, el pavo de la Envidia, el cerdo híbrido y el burro de la Gula y el asno de la Pereza (Tucker, 2015: 199).

8 «L'homme constan test semblable à l'enclume, / Qui des marteaulx ne craint la violence. / Coeur vertueux, est de telle coustume, / Que de malheur ne doubte l'insolence, / Contre tous maulx est prompt à resister. / Pour quelque effort ne se veult desister, / De paruenir en honneur, et prouesse. / Constance fait le saige persister / En son entier, et conquester noblesse» (Perriere, 1545: emb. 67).

9 «per la quale intendevano di significare, che la volontà calda, \& infocata verso la virtù, messa con istudio, e fática intorno a gli atti \& all'operazioni; le conduce a qualunque maniera, e forma di nobile, e pregiatissimo effetto. Aggiungere ancora quest'altra delle si fatte, vscita pur dalla medesima mano" (Bargagli, 1574: 213).

10 «El golpe de fortuna, aunque quebrante, / con hazienda, y salud próspero estado, / no haze mella, en la virtud constante, / ni en valor de un sano pecho honrado: / sobre la yunque, trueca en un instante / el martillo, la forma del ducado, / borrando su figura, y no por esso / de sus quilates pierde, ni del pesso" (Covarrubias, 1610: 194r) 


\section{Bibliografía}

AQUINO, Santo Tomás de (1955-1960), Suma teológica, Editorial Católica, Madrid.

BARGAGLI, Scipione (1574), Dell'imprese, Venecia.

BONARDI, Marie-Odile (2010), Les vertus dans la France baroque: représentations iconographiques et littéraires, Honoré Champion, París. BURRIS, Suzanne (1997), Pieter Bruegel the Elder's apocalyptic «Fortitude», University of North Texas, Texas, tesis doctoral.

COVARRUBIAS y HOROZCO, Sebastián de (1610), Emblemas morales, Luis Sánchez, Madrid.

FERRO, Giovanni (1623), Teatro d'imprese, Appresso Giacomo Sarzina, Venecia.

GARCÍA ARRANZ, Jose Julio (2019), Los Demonios I. El Diablo y la acción maléfica, Ediciones Encuentro, Madrid.

GARCÍA MAHÍQUES, Rafael (2009), Iconografía e Iconología: cuestiones de método, Encuentro, Madrid.

GOMBRICH, Ernst (2001), Imágenes simbólicas, Debate, Madrid.

GÓMEZ DE LA REGUERA, Francisco (1990), Empresas de los Reyes de Castilla y de León, Universidad de Valladolid, Valladolid.

IGLESIA, Nicolás de (1659), Flores de Miraflores, Diego de Nieva y Murillo, Burgos.

MÂLE, Émile (1925), L'art religieux de la fin du moyen age en France: étude sur l'iconographie du moyen age et sur ses sources d'inspiration, Armand Colin, París.

MENDO, Andrés (1662), Príncipe perfecto y ministros ajustados, documentos políticos, y morales, Horacio Boissat y George Remevs, Lyon. MENDOZA, Fray Íñigo de (1912), «Vita Christi techo por coplas por frey Yñigo de Mendoca a petiçion de la muy virtuosa señora doña Juana de Cartagena», en: Cancionero castellano del siglo XV, Bailly Bailliere, Madrid.

MONTESINOS CASTAÑEDA, María (2019), «Los fundamentos de la visualidad de la Fortaleza en el medievo. Orígenes y configuración de sus tipos iconográficos hasta el siglo XIV», Revista digital de iconografía medieval, vol. 11, n. ${ }^{0}$ 21, pp. 103-129.

- (2019), La visualidad de las virtudes cardinales, Universitat de València, València, tesis doctoral.

NORTH, Helen (1979), From myth to icon: reflections of Greek ethical doctrine in literature and art, Cornell University Press, Nueva York. O'REILLY, Jennifer (1988), Studies in the iconography of the virtues and vices in the Middle Ages, Garland Pub., Nueva York. PERRIÈRE, Guillaume de la (1545), Le théatre des bons engins, Denys lanot, París.

SAAVEDRA, Diego de (1677), L'idea del prencipe christiano, Nicolò Pezzana, Venecia.

SEBASTIÁN, Santiago (1988), Iconografía medieval, Etor, Donostia.

SOLÓRZANO PEREIRA, Juan de (1653), Emblemata centum regio-politica, G. Morras, Matriti.

TUCKER, Shawn R. (2015), The Virtues and Vices in the Arts, The Lutterworth Press, Cambridge.

TUVE, Rosemund (1963), "Notes on the virtues and vices 1: two fifteenth-century lines of dependence on thirteenth and twelfth centuries», Journal of the Warburg and Courtauld Institutes, n. ${ }^{\circ} 26$, pp. 264-303.

- (1977), Allegorical imagery: some mediaeval books and their posterity, Princeton University Press, Princeton NJ.

VIRGILIO (2003), Obras completas, Cátedra, Madrid. 